\title{
Determination of Water-Soluble Vitamins in Iraqi Honey Bee and Compare with Others Types by High - Performance Liquid Chromatography
}

\author{
Ameera H. Hamed * Saadiyah A. Dhahir* \\ Fadhil M. Abid **
}

*Department of chemistry, College of Science for Women, University of Baghdad, Baghdad, Iraq

**Ministry of Science and Technology, Baghdad, Iraq

E-mail: sadiataher@yahoo.com

Received 22/9/2015

Accepted 20/12/2015

(i) $\Theta \Theta$

This work is licensed under a Creative Commons Attribution-NonCommercialNoDerivatives 4.0 International Licens

\begin{abstract}
High-performance liquid chromatographic methods are used for the determination of water-soluble vitamins with UV-Vis. Detector. A reversed-phase high-performance liquid chromatographic has been developed for determination of water-soluble vitamins. Identification of compounds was achieved by comparing their retention times and UV spectra with those of standards solution. Separation was performed on a C18 column, using an isocratic 30\% (v/v) acetonitril in dionozed water as mobile phase at $\mathrm{pH} 3.5$ and flow rate $1.0 \mathrm{~m} / \mathrm{min}$. The method provides low detection and quantification limits, good linearity in a large concentration interval and good precision. The detection limits ranged from 0.01 to $0.025 \mu \mathrm{g} / \mathrm{ml}$. The accuracy of the method was tested by measuring average recovery values ranged between $94 \%$ - $101 \%$. For standerd solution, and 93\%-99\% of honey bee samples.
\end{abstract}

Key words: Iraqi honey, Determination, HPLC.

\section{Introduction}

As generally known, vitamins are essential substances, which are necessary for normal health and growth and in sufficient amounts should be supplied by food. If this intake is insufficient or if special dietary requirements exist, multivitamin preparation should be taken in order to prevent vitamin deficiency. Honey is a natural substance produced by bees and is a nutritious food of economic Importance worldwide [1-3]. Honey is a sweet and viscous fluid created by honeybees from the nectar of flowers
[4]. Honey is at most composed of a complex mixture of carbohydrates and other minor substances, such as organic acids, amino acids, proteins, minerals, and vitamins. In roughly all honey types, fructose predominates glucose being the second main sugar. These two account for nearly $85-95 \%$ of the honey carbohydrates. More complex sugars made up of two or more molecules of glucose and fructose constitute the residual carbohydrates, except for a trace of polysaccharide. Honey also consists of volatile substances which are 
The $2^{\text {nd }}$ National Conference of Chemistry

responsible for the characteristic aroma $[5,6]$.Vitamins are organic substances that are essential in amounts increase activity of the body. They are naturally source from plant and animal foods. The amounts of vitamins ingested from food are measured in micrograms or milligrams [7]. Eight of the watersoluble vitamins are known as the vitamin B-complex group: riboflavin (vitamin B2), niacin (vitamin B3), thiamin (vitamin B1), folate (folic acid), vitamin B6 (pyridoxine), Riboflavin Vitamin B12, biotin and pantothenic acid. The $\mathrm{B}$ vitamins are distributed in foods .Water-soluble vitamins are not stored in the body and are easily excreted while fat-soluble vitamins are cumulative in the body and the extravagant assimilation of vitamins A (Retinol) and D (Calciferol) can prove to be harmful [8-10].

Table (1): Chemical Structures of some water soluble vitamins

\begin{tabular}{c|c|c|c|}
\hline Vitamins & Thiamine \\
(B1) \\
(B2)
\end{tabular}

\section{Materials and Methods}

\section{Apparatus}

HPLC, Shimadzu LC-10A, (KoyotaJapan). Sensitive Balance, Sartorius, 4digitals, (Germany). pH-meter (Germany).,Ultra sonic bath, Karl Kolb, (Germany). , Magnetic stirrer, various temperature hot plate, UK,Evaporated (Buchi system, Germany).Centrifuge (UK).

Honey samples: honey samples were collected from different regions and market in Iraq as shown in Table (2). Samples were collected in glass bottles and stored in dark prior $25{ }^{\circ} \mathrm{C}$ to analysis.

Table (2): Source of honey bees

\begin{tabular}{|l|l|}
\hline Honey name & Source \\
\hline Flower & Arable \\
\hline Trefoil & Babble \\
\hline Seder(1) & College of Science of Women \\
\hline Seder(2) & Alnajef \\
\hline Eucalyptuses(1) & Alnajef \\
\hline Nigella sativa & Baghdad \\
\hline Mountain & Sulaymaniyah \\
\hline Eucalyptuses(2) & College of Science of Women \\
\hline Citrus & Baghdad \\
\hline Eucalyptuses(3) & ALaniber \\
\hline Olive honey & Southern of Baghdad \\
\hline Sunflower & West of Baghdad \\
\hline Germany & Germany \\
\hline American & American \\
\hline India & India \\
\hline
\end{tabular}

\section{Chemicals}

All the used chemicals were of the highest purity available analytical grade. Deionized water is used for all purposes. All glass ware, tubes, volumetric flasks, pipettes, tips and other glass were immersed in $\mathrm{HNO}_{3}(5 \% \mathrm{~V} / \mathrm{V})$ for $24 \mathrm{hr}$. then, rinsed with deionized water. All solvents in this study were grad-HPLC and obtained from BDH, Supelco company (USA) and sigma Company.

\section{Preparation stock Solutions of vitamins}

The mixture of soluble vitamins was prepared by dissolving (Thiamine. 
Riboflavin, Niacin, Pantothenic, Pyridoxal, Cyanocoblamine) $100 \mu \mathrm{g} / \mathrm{ml}$ each was diluted to $25 \mu \mathrm{g} / \mathrm{ml}$.

\section{Extraction Samples}

One gm of homogenized honey were weighed and dissolved in $1.0 \mathrm{ml}$ of ultra-pure water. Then, $0.1 \mathrm{ml}$ of $2 \mathrm{M}$ $\mathrm{NaOH}$ diluted (in order to favor the complete solubilization of the honey), and the solution was topped up to mark with ultra pure water in a $25 \mathrm{ml}$ volumetric flask. Sample solutions were injected through a PVDF $(13 \mathrm{~mm}$ and $0.45 \mathrm{~m}$ ) . The honey solution was stored in the dark at $4{ }^{\circ} \mathrm{C}$ until injection[11].

\section{Results and Discussion}

Vitamins were essential for human healths which are classified into two groups dissolved in water and soluble in fat. All water soluble vitamins are not stored in the body except B12and B6. These vitamins play an important role in vital functions such as metabolism [12].Honey consists of a mixture of complex such as compounds(flavonoids and phenolic acids, amino acid) which shows various absorption in the UV region compounds, so it is a separation method are most suitable for the extraction of these compounds. We could do by using HPLC method [13].

Optimization of the Separation of vitamins

The Effect of $\mathrm{pH}$ on the retention time

The effect of mobile phase $\mathrm{pH}$ on in reversed phase HPLC for separation mixture vitamins, to observe the effect of various $\mathrm{pH}$ on the retention time of standards. The $\mathrm{pH}$ of the system was then varied between ranges of (2.5-7.5), it was adjusted by a few drops of either $(0.1 \mathrm{M}) \mathrm{HCl}$ or $(0.1 \mathrm{M}) \mathrm{NaOH}$ solution .The effect of $\mathrm{pH}$ changes on the retention time of vitamins show in Table (3).A plot of adjusted retention time (tR) for vitamins, versus $\mathrm{pH}$ were present in Figure (1). The optimum $\mathrm{pH}$ obtained for best baseline separation of vitamins $\mathrm{pH}$ 3.5.

Table (3): Variation retention time (tR) of water soluble vitamins at different $\mathrm{pH}$ values.

\begin{tabular}{|c|c|c|c|c|c|c|}
\hline \multirow{3}{*}{ Vitamin } & \multicolumn{6}{|c|}{ Retention time (tR min) } \\
\hline & \multicolumn{6}{|c|}{ pH } \\
\hline & 2.5 & 3.5 & 4.5 & 5.5 & 6.5 & 7.5 \\
\hline Thiamine & 5.21 & 3.3 & 2.10 & 2.0 & 1.92 & 1.013 \\
\hline Niacin & 8.0 & 5.62 & 4.13 & 3.2 & 2.92 & 1.51 \\
\hline Pantothenic & 9.4 & 6.6 & 4.52 & 3.62 & 3.21 & 2.43 \\
\hline Pyridoxal & 10.1 & 8.26 & 5.61 & 4.21 & 3.82 & 2.62 \\
\hline
\end{tabular}

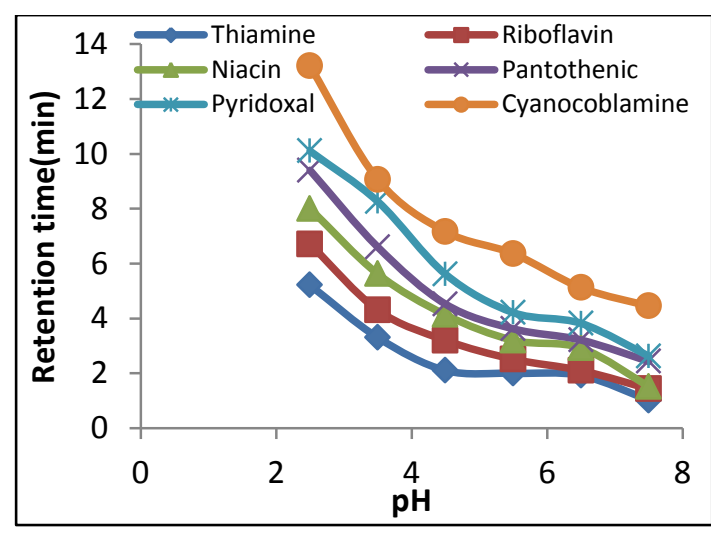

Fig. (1): Plot of adjusted retention time of water soluble vitamin versus pH.
However, it was not possible to cover $\mathrm{pH}$ range less than 2.0 and more than 8 due to instability of the packing over this region since the alkaline solution dissolves the silica support and at low $\mathrm{pH}$ breaks the $\mathrm{Si}-\mathrm{O}$ linkage. While at $\mathrm{pH}$ region between 5.0-7.0 the retention time is highly changed by the $\mathrm{pH}$ variation. This can be attributed to less effective ion-pairing reagent at the higher $\mathrm{pH}$. The $\mathrm{pH} 3.5$ was selected at the best one for vitamins. 
The $2^{\text {nd }}$ National Conference of Chemistry

Optimization of concentration of Mobile Phase in on elution of water soluble vitamin

In reveres phase methods water is one of the solvents used in the process of and it does not compete with the analyte for the adsorption sites. Washing the column another component of (e.g. acetonitrile), so that usually a modifier because it can interact with the adsorbent surface and compete with analyte molecules for the adsorption sites for dissolve this problem by Increasing the concentration of the modifier in the eluent leads to the decreasing of the analyte retention time. This study was done by using deionized water acidified with and acetonitrile in different ratios. This stage was done by the system of HPLC. The results show generally that the retention time was decreased with increasing the $\%$ of acetonitrile. This effect has been attributed to a decrease of the surface concentration of the counter-molecule because of the competition by the solvent. Table (4) shows variation of retention time of water soluble vitamins

Table (4): Variation of retention time (tR) of water soluble vitamins on reversed phase at different $\%$ acetonitrile flow rate $1.0 \mathrm{ml} / \mathrm{min}$

\begin{tabular}{|c|c|c|c|c|c|c|}
\hline \multirow{3}{*}{ Vitamin } & \multicolumn{6}{|c|}{ Retention time (min.) } \\
\hline & \multicolumn{6}{|c|}{ Concentration of acetonitrile $(\%)$} \\
\hline & $5 \%$ & $10 \%$ & $20 \%$ & $\mathbf{3 0 \%}$ & $40 \%$ & $\mathbf{5 0 \%}$ \\
\hline Thiamine & 8.46 & 6.25 & 4.41 & 3.37 & 2.21 & 1.54 \\
\hline Riboflavin & 10.6 & 8.51 & 6.21 & 5.81 & 4.2 & 3.1 \\
\hline Niacin & 11.54 & 9.26 & 7.51 & 6.37 & 3.89 & 3.5 \\
\hline Pantothenic & 13.4 & 10.34 & 8.92 & 7.6 & 5.21 & 4.3 \\
\hline Pyridoxal & 14.0 & 12.7 & 11.8 & 10.72 & 8.21 & 5.3 \\
\hline Cyanocoblamine & 18.4 & 15.6 & 13.2 & 11.68 & 9.34 & 7.51 \\
\hline
\end{tabular}

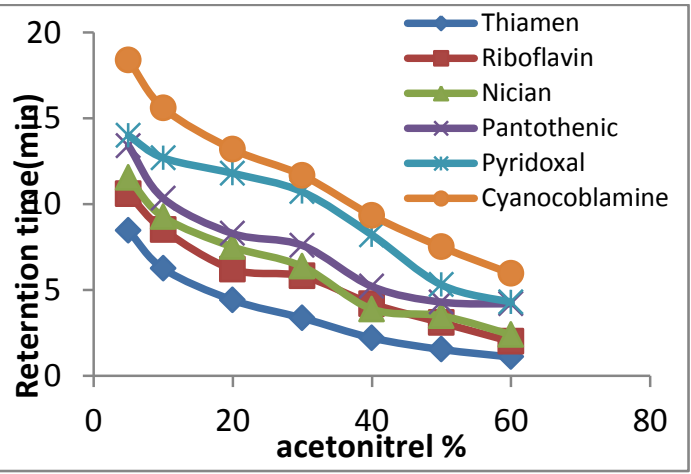

Fig. (2): The Effect of percentage of acetonitrile of separation water soluble vitamins

The Effect of Flow Rate on Separation of water soluble vitamins

HPLC column affected with Increase the flow rate by generating high pressure and reducing the analysis time. So, one must choose a flow rate that is appropriate for HPLC system and column. A higher than usual flow rate may adversely affect the quality of the chromatography not giving the analyte sufficient time to interact with the stationary phase. Faster is not always better. Table (5) and Figure (3) show effect of flowe rate for separation water soluble vitamins. Water Soluble vitamin changed smoothly with a change in flow rate $A$ change in flow rate from (1.6 $\mathrm{ml} / \mathrm{min}$ to $0.6 \mathrm{ml} / \mathrm{min}$ ) . Caused a change in the total analysis of time from 5.16 minutes from7.56 minutes to 17.2 minutes for Water Soluble vitamin. $1 \mathrm{ml}$ /min gave acceptable separation time for water soluble vitamins.

Table (5): The Effect of flow rate on retention time of water soluble vitamins

\begin{tabular}{|l|l|l|l|l|l|l|}
\hline $\begin{array}{l}\text { Flow rate } \\
\text { ml/min }\end{array}$ & \multicolumn{6}{|l|}{ Retention time (min.) } \\
\hline Vitamin & $\mathbf{0 . 6}$ & $\mathbf{0 . 8}$ & $\mathbf{1 . 0}$ & $\mathbf{1 . 2}$ & $\mathbf{1 . 4}$ & $\mathbf{1 . 6}$ \\
\hline Thiamine & 2.81 & 3.0 & 3.37 & 3.72 & 4.02 & 4.51 \\
\hline Riboflavin & 4.0 & 4.92 & 5.81 & 6.31 & 7.51 & 8.6 \\
\hline Niacin & 4.3 & 5.21 & 6.37 & 7.21 & 8.91 & 11.2 \\
\hline Pantothenic & 4.8 & 6.51 & 7.91 & 9.8 & 11.7 & 13.65 \\
\hline Pyridoxal & 6.51 & 8.21 & 10.76 & 12.5 & 14.3 & 16.1 \\
\hline $\begin{array}{l}\text { Cyanocobl } \\
\text { amine }\end{array}$ & 17.26 & 15.31 & 13.42 & 11.72 & 9.72 & 7.56 \\
\hline
\end{tabular}


The $2^{\text {nd }}$ National Conference of Chemistry

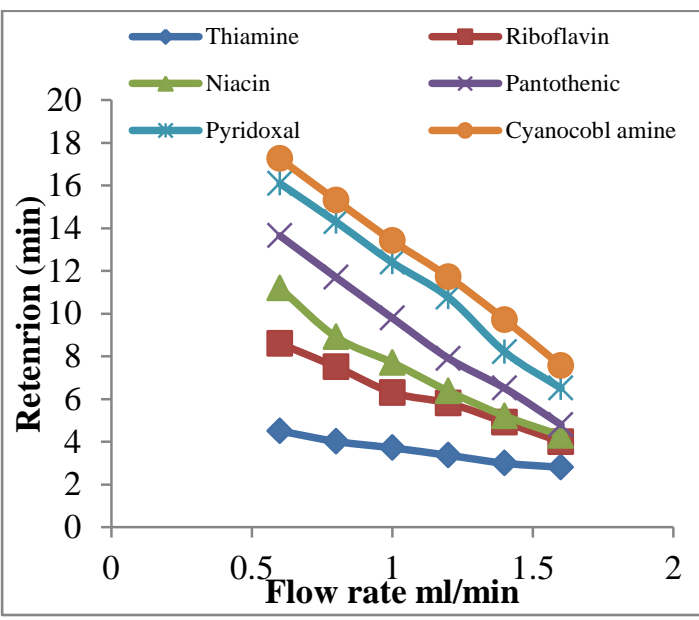

Fig. (3): Retention time as a function of flow rate for Water soluble vitamins.
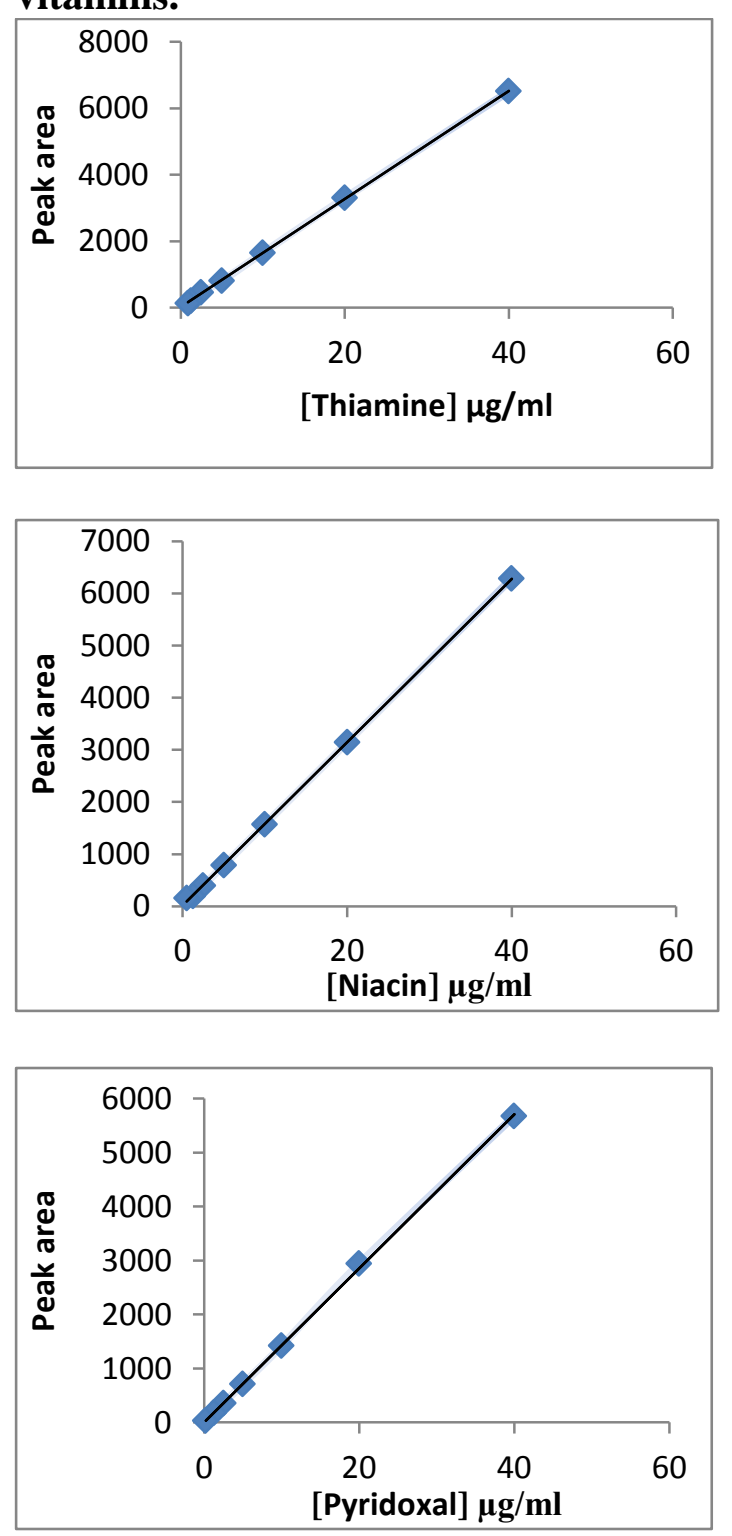

Table (6): The optimum working conditions for the determination of water soluble vitamins

\begin{tabular}{|l|l|}
\hline Parameters & $\begin{array}{l}\text { Value of water soluble } \\
\text { vitamins }\end{array}$ \\
\hline Sample volume & $20 \searrow \mathrm{L}$ \\
\hline Column & $\mathrm{C} 18(50 \times 4.6 \mathrm{~mm}$, i.d) \\
\hline Organic modifier & $30 \%$ \\
\hline $\mathrm{pH}$ & $(3.5)$ \\
\hline Flow rate & $1.0 \mathrm{ml} / \mathrm{min}$ \\
\hline$\swarrow$ maximum & $210 \mathrm{~nm}$ \\
\hline
\end{tabular}

\section{Calibration curve}

The optimum condition for the separation of amino acid and water soluble vitamin were tabulated in Table (6)
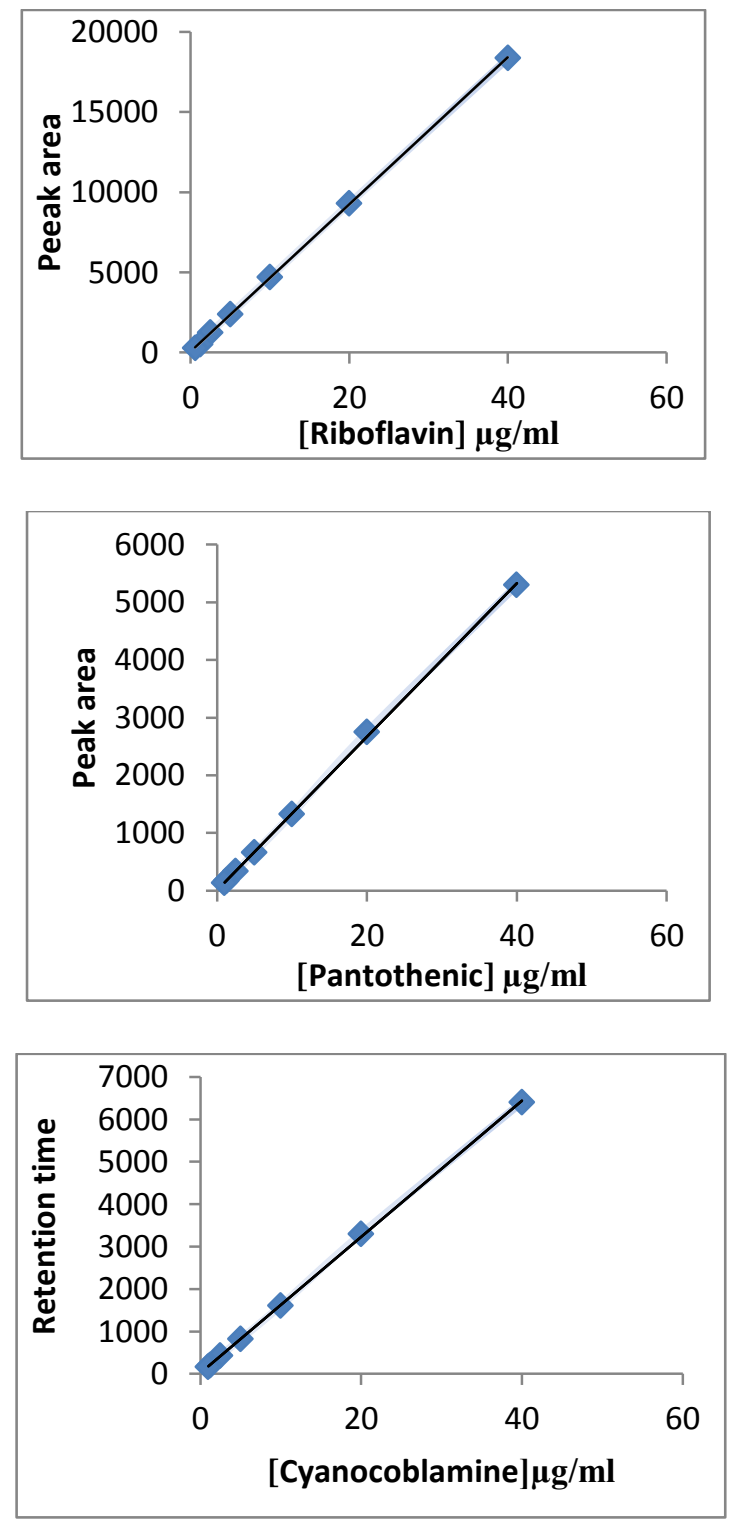

Fig. (4): Calibration curve of water soluble vitamins 
The $2^{\text {nd }}$ National Conference of Chemistry

Table (8): Error \% and Rec \% results for analysis of Water soluble vitamins in standard solutions

\begin{tabular}{|c|c|c|c|c|c|}
\hline \multirow{2}{*}{ Vitamins } & \multicolumn{3}{|c|}{ Conc. of Vitamins $\boldsymbol{\mu g} / \mathbf{m l}$} \\
\cline { 2 - 7 } & Present & Found & Error \% & Rec \% & RSD\% \\
\hline \multirow{3}{*}{ Thiamine } & 2.00 & 1.95 & 2.50 & 97.50 & 0.79 \\
\cline { 2 - 7 } & 7.00 & 7.06 & -1.00 & 101.00 & 0.66 \\
\cline { 2 - 7 } & 12.00 & 11.61 & 3.30 & 96.70 & 0.30 \\
\hline \multirow{3}{*}{ Riboflavin } & 2.00 & 2.01 & -1.00 & 101.00 & 0.24 \\
\cline { 2 - 7 } & 7.00 & 7.13 & 1.86 & 102.00 & 0.83 \\
\cline { 2 - 7 } & 12.00 & 11.85 & 1.25 & 98.80 & 0.32 \\
\hline \multirow{3}{*}{ Niacin } & 2.00 & 1.98 & 1.00 & 99.00 & 0.79 \\
\cline { 2 - 7 } & 7.00 & 6.88 & 1.70 & 98.30 & 0.92 \\
\cline { 2 - 7 } & 12.00 & 11.75 & 2.08 & 97.92 & 0.35 \\
\hline \multirow{3}{*}{ Pantothenic } & 2.00 & 1.92 & 4.00 & 96.00 & 0.97 \\
\cline { 2 - 7 } & 7.00 & 7.18 & -3.00 & 103.00 & 0.28 \\
\cline { 2 - 7 } & 12.00 & 11.75 & 2.08 & 97.92 & 0.80 \\
\hline \multirow{3}{*}{ Pyridoxal } & 2.00 & 1.88 & 6.00 & 94.00 & 0.90 \\
\hline & 7.00 & 6.65 & 5.00 & 95.00 & 0.33 \\
\hline
\end{tabular}

Table (9): Error \% and Rec \% results for analysis of Water soluble vitamins in honey samples.

\begin{tabular}{|c|c|c|c|c|c|c|c|}
\hline \multirow{2}{*}{ Type of honey } & \multicolumn{7}{|c|}{ Conc. of vitamins $\mathrm{mg} / \mathrm{kg}$} \\
\hline & Vitamins & B1 & B2 & B3 & B5 & B6 & B12 \\
\hline \multirow{5}{*}{ Flower } & Present & 21.00 & 3.03 & ------ & 3.60 & 3.50 & 3.10 \\
\hline & Added & 3.00 & 3.00 & 3.00 & 3.00 & 3.00 & 3.00 \\
\hline & Found & 23.58 & 6.00 & ------- & 6.52 & 6.25 & 5.98 \\
\hline & $\operatorname{Rec} \%$ & 98.30 & 99.50 & ------- & 98.8 & 96.10 & 98.03 \\
\hline & Error\% & 1.17 & 0.50 & ----- & 1.20 & 3.90 & 1.97 \\
\hline \multirow{5}{*}{ Trefoil } & Present & 4.20 & 10.90 & 4.50 & 1.72 & 3.85 & 3.15 \\
\hline & Added & 3.00 & 3.00 & 3.00 & 3.00 & 3.00 & 3.00 \\
\hline & Found & 7.00 & 13.78 & 7.35 & 4.70 & 6.75 & 6.10 \\
\hline & $\operatorname{Rec} \%$ & 97.20 & 99.14 & 98.00 & 99.58 & 98.54 & 99.19 \\
\hline & Error\% & 2.80 & 0.86 & 2.00 & 0.42 & 1.46 & 0.81 \\
\hline \multirow{5}{*}{ Seder (1) } & Present & 27.39 & 3.03 & -------- & 3.60 & 3.50 & 3.10 \\
\hline & Added & 3.00 & 3.00 & 3.00 & 3.00 & 3.00 & 3.00 \\
\hline & Found & 30.20 & 5.97 & ------- & 6.52 & 6.32 & 6.00 \\
\hline & $\operatorname{Rec} \%$ & 99.37 & 99.00 & ------- & 98.80 & 970 & 98.37 \\
\hline & Error $\%$ & 0.63 & 1.00 & ---- & 1.20 & 2.80 & 1.63 \\
\hline \multirow{5}{*}{ Seder (2) } & Present & 2.40 & 2.60 & 4.24 & 7.50 & 4.40 & 3.6 \\
\hline & Added & 3.00 & 3.00 & 3.00 & 3.00 & 3.00 & 3.0 \\
\hline & Found & 5.33 & 5.43 & 7.10 & 10.38 & 7.23 & 6.41 \\
\hline & $\operatorname{Rec} \%$ & 98.7 & 97.00 & 98.07 & 99.00 & 97.7 & 97.12 \\
\hline & Error\% & 1.30 & 3.00 & 1.93 & 1.10 & .29 & 2.96 \\
\hline \multirow{5}{*}{ Eucalyptuses (1) } & Present & 3.20 & 3.10 & 3.09 & 3.50 & 3.5 & 2.86 \\
\hline & Added & 3.00 & 3.00 & 3.00 & 3.00 & 3.00 & 3.00 \\
\hline & Found & 6.00 & 6.00 & 5.96 & 6.35 & 6.40 & 5.80 \\
\hline & $\operatorname{Rec} \%$ & 96.80 & 98.4 & 98.36 & 97.30 & 98.5 & 97.97 \\
\hline & Error\% & 3.20 & 1.64 & 1.66 & 2.30 & 1.54 & 1.03 \\
\hline \multirow{5}{*}{ Nigella sativa } & Present & ------ & 5.75 & 14.50 & 2.70 & 4.35 & 2.59 \\
\hline & Added & 3.00 & 3.00 & 3.00 & 3.00 & 3.00 & 3.00 \\
\hline & Found & ------ & 8.70 & 17.30 & 5.68 & 7.20 & 5.48 \\
\hline & $\operatorname{Rec} \%$ & ------ & 99.43 & 98,86 & 99.65 & 98 & 98.03 \\
\hline & Error\% & ----- & 0.57 & 1.10 & 0.35 & 2.0 & 1.97 \\
\hline \multirow{5}{*}{ Mountain } & Present & ----- & 1.30 & 2.40 & 6.80 & 4.79 & 4.0 \\
\hline & Added & 3.0 & 3.0 & 3.0 & 3.0 & 3.0 & 3.0 \\
\hline & Found & $\begin{array}{ll}--- \\
\end{array}$ & 4.28 & 5.3 & 9.65 & 7.5 & 6.80 \\
\hline & $\operatorname{Rec} \%$ & ----- & 99.53 & 98.2 & 98.15 & 96.3 & 97.1 \\
\hline & Error\% & ------ & 0.47 & 1.9 & 1.55 & 3.7 & 2.9 \\
\hline \multirow{5}{*}{ Eucalyptuses (2) } & Present & 2.35 & 2.30 & 4.7 & 2.4 & 2.17 & 2.5 \\
\hline & Added & 3.0 & 3.0 & 3.0 & 3.0 & 3.0 & 3.0 \\
\hline & Found & 5.3 & 5.25 & 7.61 & 5.31 & 5.1 & 5.33 \\
\hline & Rec\% & 99.07 & 99.06 & 98.83 & 98.33 & 98.64 & 96.91 \\
\hline & Error\% & 1.3 & 0.94 & 1.18 & 1.67 & 1.37 & 3.19 \\
\hline \multirow{2}{*}{ Citrus } & Present & ------- & 4.40 & 4.7 & 6.1 & 3.83 & 3.52 \\
\hline & Added & 3.0 & 3.0 & 3.0 & 3.0 & 3.0 & 3.0 \\
\hline
\end{tabular}


The $2^{\text {nd }}$ National Conference of Chemistry

\begin{tabular}{|c|c|c|c|c|c|c|c|}
\hline & Found & $\begin{array}{l}------ \\
\end{array}$ & 7.12 & 7.6 & 9.03 & 6.78 & 6.33 \\
\hline & Rec\% & ------ & 96.1 & 98.7 & 99.23 & 99.27 & 97.09 \\
\hline & Error\% & ----- & 3.9 & 1.3 & 0.77 & 0.73 & 2.91 \\
\hline \multirow{5}{*}{ Eucalyptuses (3) } & Present & 4.50 & 1.15 & 6.15 & 11.3 & 3.9 & 4.2 \\
\hline & Added & 3.0 & 3.0 & 3.0 & 3.0 & 3.0 & 3.0 \\
\hline & Found & 7.23 & 4.10 & 9.0 & 14.0 & 6.78 & 7.10 \\
\hline & $\operatorname{Rec} \%$ & 96.40 & 96.00 & 98.36 & 97.9 & 98.26 & 98.61 \\
\hline & Error\% & 3.60 & 1.20 & 1.67 & 2.10 & 1.74 & 1.39 \\
\hline \multirow{5}{*}{ Olive } & Present & ------ & 6.85 & 2.27 & 1.83 & 2.0 & 1.80 \\
\hline & Added & 3.0 & 3.0 & 3.0 & 3.0 & 3.0 & 3.0 \\
\hline & Found & ----- & 9.79 & 5.18 & 4.8 & 4.9 & 4.72 \\
\hline & Rec\% & ------ & 99.4 & 98.29 & 99.37 & 98 & 98.33 \\
\hline & Error $\%$ & ----- & 0.60 & 1.71 & 0.63 & 2.0 & 1.67 \\
\hline \multirow{5}{*}{ Sunflower } & Present & ----- & 1.30 & 16.40 & 1.25 & 5.16 & 1.7 \\
\hline & Added & 0.3 & 3.0 & 3.0 & 3.0 & 3.0 & 3.0 \\
\hline & Found & ----- & 4.22 & 19.30 & 4.20 & 8.10 & 4.66 \\
\hline & Rec\% & ----- & 98.13 & 99.48 & 98.82 & 99.26 & 99.15 \\
\hline & Error\% & ---- & 1.86 & 0.52 & 1.18 & 0.74 & 0.85 \\
\hline \multirow{5}{*}{ Germany } & Present & ----- & 5.80 & 2.85 & 6.5 & 3.0 & 5.0 \\
\hline & Added & 3.0 & 3.0 & 3.0 & 3.0 & 3.0 & 3.0 \\
\hline & Found & ----- & 8.70 & 5.80 & 9.4 & 5.89 & 7.72 \\
\hline & Rec\% & ---- & 98.86 & 99.14 & 98.9 & 98.17 & 96.5 \\
\hline & Error\% & ----- & 1.14 & 0.86 & 1.1 & 1.83 & 3.5 \\
\hline \multirow{5}{*}{ American } & Present & ----- & 8.1 & 6.32 & 6.54 & 1.64 & 5.35 \\
\hline & Added & 3.0 & 3.0 & 3.0 & 3.0 & 3.0 & 3.0 \\
\hline & Found & ---- & 11.05 & 9.12 & 9.33 & 4.6 & 8.30 \\
\hline & $\operatorname{Rec} \%$ & ----- & 99.55 & 97.85 & 97.79 & 99.14 & 99.4 \\
\hline & Error\% & ----- & 0.45 & 2.19 & 2.25 & 0.86 & 0.6 \\
\hline \multirow{5}{*}{ India } & Present & 21.30 & 1.50 & 5.40 & 5.90 & 10.75 & 5.30 \\
\hline & Added & 3.0 & 3.0 & 3.0 & 3.0 & 3.0 & 3.0 \\
\hline & Found & 24.11 & 4.46 & 8.2 & 8.77 & 13.60 & 8.26 \\
\hline & Rec\% & 99.21 & 99.11 & 97.61 & 98.54 & 98.9 & 99.52 \\
\hline & Error\% & 0.78 & 0.89 & 2.4 & 1.46 & 1.1 & 0.48 \\
\hline
\end{tabular}

\section{Resolution Measurement}

Column performance traditionally has been defined by its reproducibility. Height equivalent to the theoretical plates, HETP $(\mathrm{H})$ and number of plates although useful., but these parameters do not provide sufficient information for properly evaluating column usefulness, capacity factor $\overline{\mathrm{K}}$ was also recommended for column evaluation ${ }^{[14]}$. The results listed in Table (10) show the column parameters for an optimum separation of water soluble vitamins

Table (10): Retention times, capacity factors, and separation factors shows optimum condition for separation of water soluble vitamins

\begin{tabular}{|l|l|l|l|l|l|}
\hline Compound & $\begin{array}{l}\text { tR } \\
\text { min }\end{array}$ & $\bar{K}$ & $\Rightarrow$ & N & $\mathbf{R}$ \\
\hline Thiamine & 3.900 & 2.900 & ----- & 521.34 & -------- \\
\hline Riboflavin & 4.355 & 3.355 & 1.2 & 2626 & 0.16 \\
\hline Niacin & 5.628 & 4.630 & 1.4 & 4387 & 1.54 \\
\hline Pantothenic & 6.606 & 5.610 & 1.2 & 6044 & 2.75 \\
\hline Pyridoxal & 8.265 & 7.265 & 1.3 & 18078 & 2.09 \\
\hline $\begin{array}{l}\text { Cyanocob } \\
\text { lamine }\end{array}$ & 9.069 & 8.100 & 1.12 & 1139 & 0.804 \\
\hline
\end{tabular}

The partition ratio $\bar{K}$, which is commonly called the capacity factor. The capacity factor $\overline{\mathrm{K}}$ for water soluble vitamin chromatographic on ODS column were ranged (2.9-8.265) for the analyzed samples as listed in Table (10).The column selectivity, originally called the separation factor $\Rightarrow$ is defined as the ratio of the capacity factors of two adjacent peaks $\Rightarrow=\overline{\mathrm{K}}_{2} / \overline{\mathrm{K}}_{1}($ The $\Rightarrow$ represents the separation factor or selectivity representing capacity factor between the two components $\Rightarrow$ values for water soluble vitamins (1.2-1.4) as listed in Table (10) When the value of $\Rightarrow 1$ or more, that means we obtained base line separation for all the eluted mixture. Therefor the optimum separation condition we got, gave mixture under this study, The phase separation mechanism in ODS column depends on the hydrophobic binding interaction between the $\mathrm{R}$ group of organic compounds and immobilized 
hydrophobic ligand of the stationary phase .The different values of retention times due to interaction between different $\mathrm{R}$ groups of organic compound and octadecyle group of the stationary phase governed the mechanism of the retention time. This decreased hydrophilic or hydrophobic interaction with the stationary [14].
Application of the Optimum Conditions for the separation and determination of Water Soluble Vitamin

The analysis of water soluble vitamins in variation honey samples was applied under the optimum condition. The optimum conditions for the separation of water soluble vitamins were obtained by variation in the organic modifier, $\mathrm{pH}$ and flow rate. The experimental results of these studies observed the optimum conditions, which gave a base line separation for the whole mixture $30 \%$ acetontrile water soluble vitamins respectively, $\mathrm{pH} 3.5$ and flow rate $1 \mathrm{ml} / \mathrm{min}$ for ,as shown in typical chromatogram Figures (5) and (6)

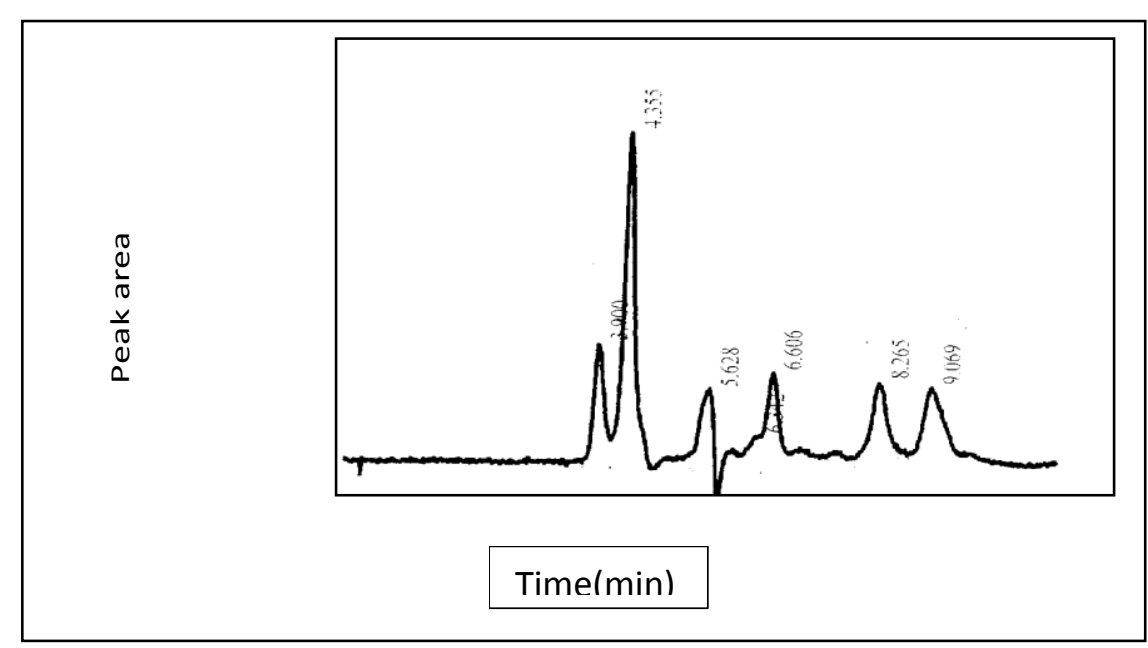

Fig. (5): standard mixture of water soluble vitamins on reversed phase column (50×4.6mm.) using $30 \%$ flow $1.0 \mathrm{ml} / \mathrm{min}$ UV detector $210 \mathrm{~nm}$.
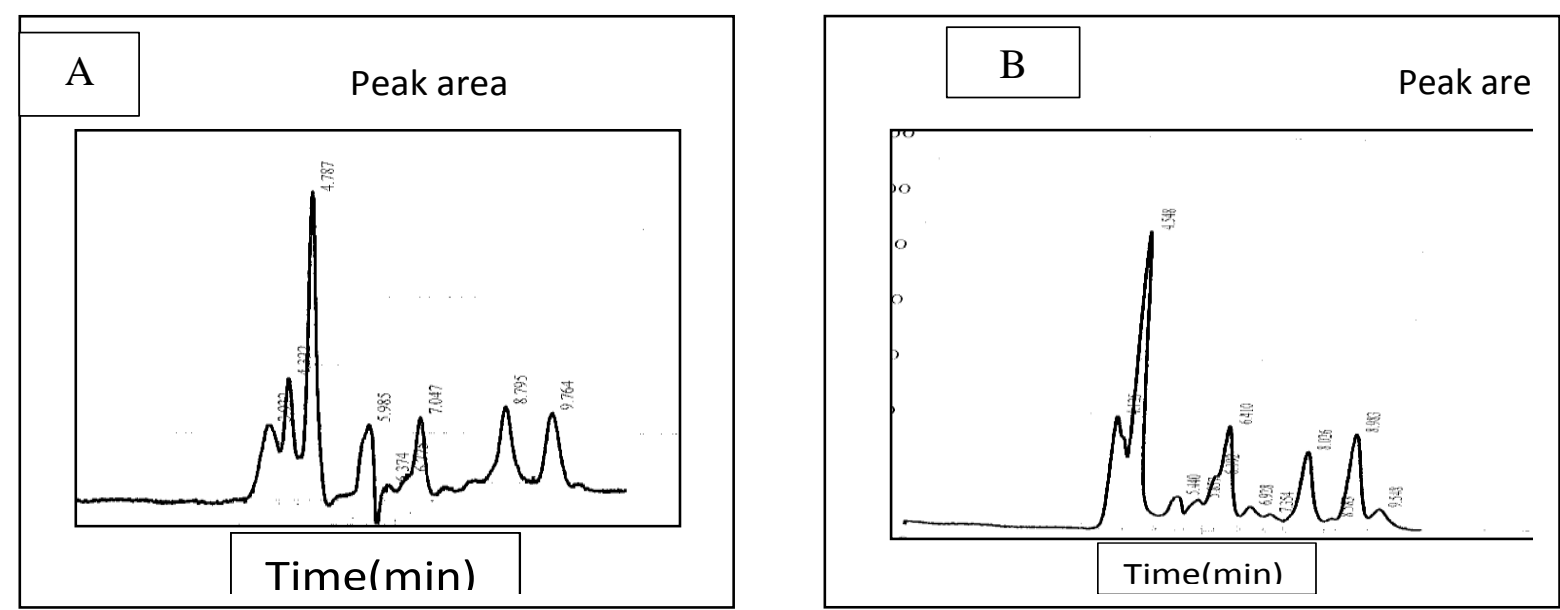


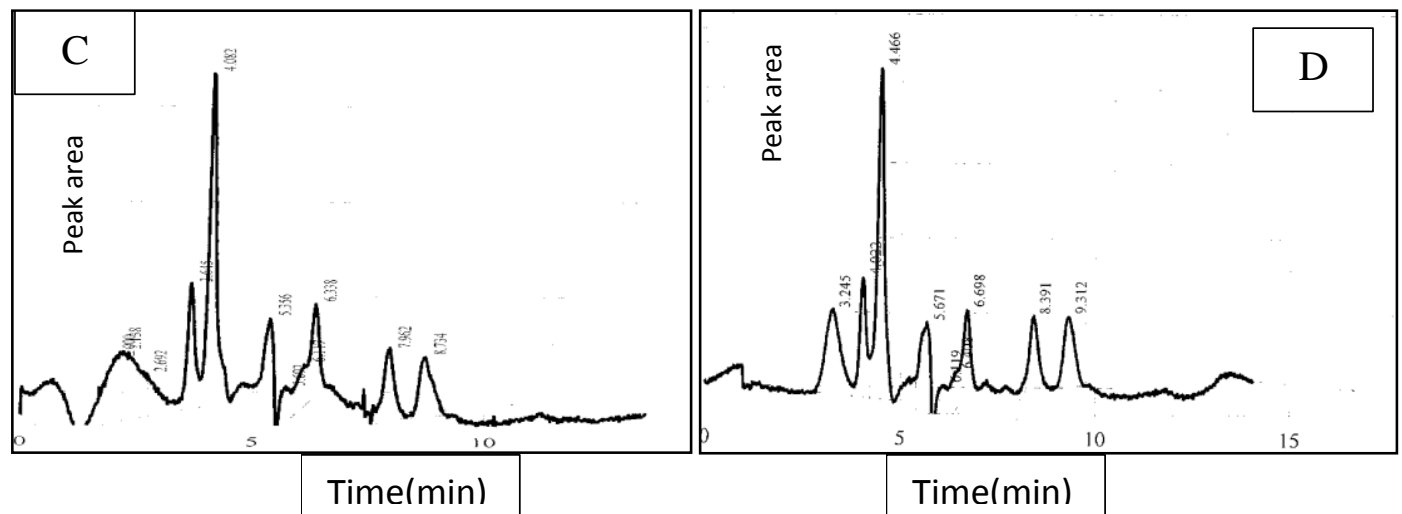

Fig. (6): Separation mixture of water soluble vitamins in Honey samples on reversed phase column $(50 \times 4.6 \mathrm{~mm}$.) using $30 \%$ acetonitrile flow $1.0 \mathrm{ml} / \mathrm{min} \mathrm{UV}$.

Table (11): Concentration of Water soluble vitamins compounds in honey bee under study values are expressed in $\mu \mathrm{g} / 100 \mathrm{gm}$ as mean $\pm \mathrm{Sd}$ detector $210 \mathrm{~nm}(\mathrm{~A}=$ Trefoil, $B=$ Mountain (3), C Sunflower ,D=Seder(2))

\begin{tabular}{|c|c|c|c|c|c|c|}
\hline Type of honey & B1 & B2 & B3 & B5 & B6 & B12 \\
\hline Flower & $21.0 \pm 1.000$ & $3.033 \pm 1.528$ & ------ & $3.61 \pm 1.000$ & $3.59 \pm 1.000$ & $3.14 \pm 1.000$ \\
\hline Trefoil & $4.30 \pm 1.528$ & $10.97 \pm 1.528$ & $4.48 \pm 1.528$ & $1.75 \pm 1.5275$ & $3.897 \pm 2.08$ & $3.18 \pm 1.528$ \\
\hline Seder(1) & $27.93 \pm 1.528$ & $3.047 \pm 1.528$ & $3.917 \pm 1.528$ & $2.91 \pm 1.000$ & $2.77 \pm 1.000$ & $2.69 \pm 1.000$ \\
\hline Seder(2) & $2.40 \pm 2.000$ & $2.62 \pm 2.00$ & $2.598 \pm 1.528$ & $7.60 \pm 2.000$ & $4.40 \pm 1.53$ & $3.61 \pm 1.000$ \\
\hline $\begin{array}{c}\text { Eucalyptuses } \\
\text { (1) }\end{array}$ & $3.31 \pm 1.000$ & $3.09 \pm 1.000$ & $4.26 \pm 1.528$ & $3.52 .33 \pm 1.16$ & $3.55 \pm 2.646$ & $2.86 \pm 1.528$ \\
\hline Nigella sativa & ----- & $5.77 \pm 1.000$ & $14.77 \pm 1.528$ & $2.72 \pm 2.0817$ & $4.36 \pm 1.526$ & $2.50 \pm 2.000$ \\
\hline Mountain & ----- & $1.303 \pm 1.528$ & $2.42 \pm 1.5275$ & $6.82 \pm 2.517$ & $4.79 \pm 2.52$ & $3.97 \pm 2.517$ \\
\hline Eucalyptuses (2) & $2.36 \pm 1.528$ & $2.30 \pm 2.517$ & $3.91 \pm 2.082$ & $2.42 \pm 1.000$ & $2.17 \pm 2.517$ & $2.50 \pm 1.000$ \\
\hline Citrus & ----- & $4.437 \pm 3.215$ & $4.68 \pm 2.646$ & $6.10 \pm 1.528$ & $3.83 \pm 4.042$ & $3.49 \pm 1.155$ \\
\hline Eucalyptuses(3) & $4.51 \pm 2.081$ & $1.12 \pm 2.517$ & $6.14 \pm 3.606$ & $11.33 \pm 1.528$ & $3.91 \pm 1.528$ & $4.20 \pm 1.528$ \\
\hline Olive & ----- & $6.857 \pm 3.055$ & $2.26 \pm 2.646$ & $1.807 \pm 2.08$ & $2.00 \pm 1.000$ & $1.81 \pm 0.876$ \\
\hline Sunflower & ----- & $1.303 \pm 1.528$ & $16.42 \pm 2.646$ & $1.27 \pm 2.0817$ & $5.16 \pm 1.528$ & $2.53 \pm 1.15$ \\
\hline Germany & ----- & $5.81 \pm 1.000$ & $2.86 \pm 3.215$ & $6.50 \pm 1.000$ & $3.01 \pm 1.528$ & $5.00 \pm 5.508$ \\
\hline American & ---- & $8.12 \pm 1.528$ & $6.32 \pm 2.082$ & $6.54 \pm 4.042$ & $1.64 \pm 1.000$ & $5.37 \pm 0.674$ \\
\hline India & $21.36 \pm 1.528$ & $1.54 \pm 1.528$ & $5.40 \pm 1.000$ & $5.90 \pm 1.000$ & $10.78 \pm 0.054$ & $5.34 \pm 1.000$ \\
\hline
\end{tabular}

Water -soluble vitamins were measured in different types of honey sample from Iraqi markets which showed various concentrations in table (11) the highest level for B1 ,B2,B3 ,B5,B6,B12 ( in Seder(1) honey $27.93 \mathrm{mg} / \mathrm{kg}$, Trefoil honey $10.97 \mathrm{mg} / \mathrm{kg}$, Sunflower honey $16.45 \mathrm{mg} / \mathrm{kg}$, Eucalyptuses(3)honey $11.33 \mathrm{mg} / \mathrm{kg}$, Olive honey $2.0 \mathrm{mg} / \mathrm{kg}$, Sunflower2.53 $\mu \mathrm{g} / 100 \mathrm{gm}$ ) and lowest level in (Seder(2) honey $2.4 \mathrm{mg} / \mathrm{kg}$, Eucalyptuses(3)honey $1.12 \mathrm{mg} / \mathrm{kg}$, Olive honey $2.26 \mathrm{mg} / \mathrm{kg}$, Sunflower honey $1.27 \mathrm{mg} / \mathrm{kg}$, American honey
16.4,Olive honey $1.81 \mu \mathrm{g} / 100 \mathrm{gm})$. We can compare different types of honey samples which found high level for vitamin B2, B3, B5 (920, 278,700) $\mathrm{mg} / \mathrm{kg}$ in different location [15] and B6 in Brazilin honey $4074 \mathrm{mg} / \mathrm{kg}$ [16].

\section{Conclusions}

This study was focused to determine Water -soluble vitamins in Iraqi honey samples that produce in University of Baghdad College of Sciences for 
Women and other located and compared with other kinds. The obtained results found that it is possible to take advantage of this method that was developed in the set and extract the active compounds in the honey which is water- soluble vitamins of the importance vital. The extraction and separation using a HPLC technique high response, sensitivity and speed too high in separation. Close results and agreement of Iraqi honey samples when compared by extraction methods for honey samples with literature.

\section{References:}

[1] Li, Y. Q. H.; Yan, J. Y.; Ma, Q. W.; J.-We Zhang, and Xi, G. X. 2013. High Performance Liquid Chromatographic Determination of Phenolic Compounds in Propolis, Tropical J. of Pharm. Res., 12 (5): 771-776,

[2] Hamdy, A. A; Ismail, H. M.; ALAhwal, A. E. and Gomaa, N. F., 2009. Determination of Flavonoid and Phenolic Acid Contents of Clover, Cotton and Citrus Floral Honeys,J. Eg. Public Health Assoc, 84(3): 245-257

[3] Nigussie, K.; Subramanian, P. A. and Mebrahtu, G. 2012. Physicochemical analysis of Tigray honey: An attempt to determine major quality markers of honey,Bull. Chem. Soc. Ethiop.,26(1): 127-133

[4] Rehman, S.; Khan Z. F.; and Maqboo, T. 2008. Physical and spectroscopic characterization of Pakistani honey Cien. Inv. Agr., 35(2): 199-204

[5]Shahnawaz, M.; Sheikh, S. A; Abdul Razaq, M. H. and Khan, S. S. 2013. A study on the determination of physicochemical properties of honey from different valleys of GilgitBaltistan, Int. J. of Agri. Sci Res, 2(2): 049-053

[6] Moneim, A.; Sulieman, B. A. and Salih, Z. A.; 2013. Quality
Evaluation of Honey Obtained from Different Sources, J.Food and Public Health, 3(3): 137-141

[7] Otemuyiwa, O. I. and Adewusi, A. 2013. Simultaneous high performance liquid chromatography analysis of water soluble vitamins in some foods prepared by a Nigerian eatery, Afr. J. Food Sci, 11: 415-420

[8] Bellows, L. and Moore, R. 2012. Water-Soluble Vitamins: B-Complex and Vitamin C, J. F. and Nu. Se., Fact Sheet n. 9.312

[9] Ozkok, A.; Bruce, D. and Kadriye, S.; 2010.Total Phenolic Acid and Total Flavonoid Content of Turkish Pine Honeydew Honey, J. of Api. and Api Med. Sci., 2 (2):.65 -71

[10] Smith, M. S.; Line Mc Donald, A. R. and Densie WeBB, 1998. Complete Book of vitamins and Minerals, International, Ltd,

[11] Meda, A.; Lamien, Ch. Eu.; Marco, R.; Jeanne M. and. Odile, G. N.; 2005. Determination of the total phenolic, flavonoid and proline Contents in Burkina Fasan Honey, as well as their radical scavenging activity, J. F. Chem., 91: 571-577.

[12] Sawheney, S. K. and Singh, R., 2006. Introduction Practical Biochemistry, Int. Pra. Bio., Nar. Publishing House , India, Chap.6,.99

[13]Christian, G. D. 2004. Analytical Chemistry. Six Edition, John Wiley and Sons, Inc.

[14] Currell G.; 2000. Analytical Instrumentation Performance Characteristics and Quality, John Wiley and Sons Inc., chap. 8, Chap. 9

[15] Ciulua, Ma.; Solinas, Si., Floris, Ig.; Angelo P., Maria, I. Pi.; Paola C. Pi., Spanoa N. and Sanna G., 2011. RP-HPLC detection of water-soluble vitamins in honey" J. Talanta, 83: 924-929.

[16] Presoto A. E. F.; Magda, D. G. R. and de Almeida-Muradian, Li., B., 2004. Simultaneous High Performance Liquid 
Chromatographic Analysis of Jelly" J. Braz. Chem. Soc., 15(1): Vitamins B1, B2 and B6 in Royal 136-139.

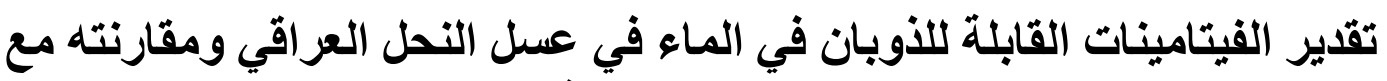

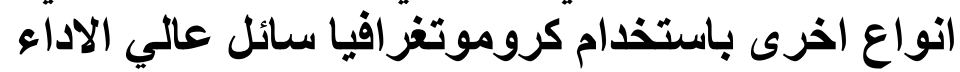

*اضل محسن عبد**

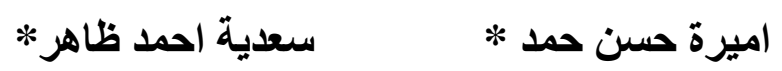

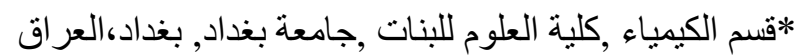

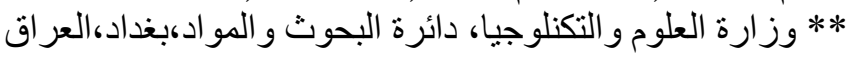

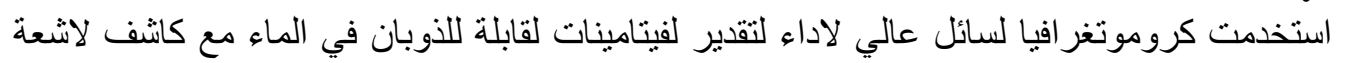

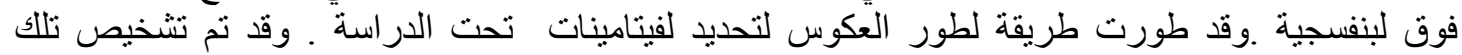

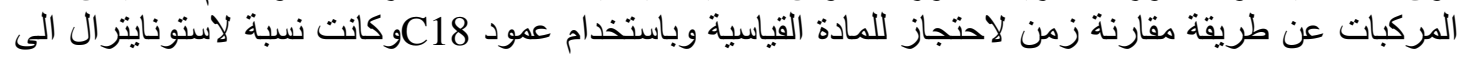

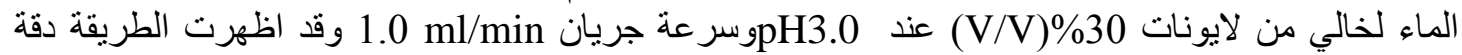
وتو افقية جيدة في مدى تر اكيز تتراوح (V)

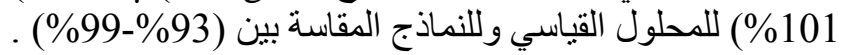

HPLC الكلمات المفتاحية :العسل العر اقي ،تقدير 